\title{
Bir Örgütsel Ombudsmanlık Uygulaması Olarak Yükseköğretim Ombudsmanlık Ofisleri
}

\author{
Metin Kaya \\ 'Bayburt Üniversitesi, Bayburt Eğitim Fakültesi, Bayburt
}

ORCID: M. Kaya (0000-0002-8287-4929)

\begin{abstract}
Özet
Klasik ombudsmanlık kurumlarının gelișimi ile birlikte örgütsel ombudsmanlık ofisleri da gelişmektedir. 1960 yılların başından itibaren büyük işletmelerde, kamu hizmeti yürüten kurumlarda ve özellikle yükseköğretim kurumlarında örgütsel ombudsmanlık ofisleri yaygınlaşmaya başlamıştır. Bu çalışmada yükseköğretim kurumları bağlamında örgütsel ombudsmanlık bürolarının rolleri, ișlevleri ve tarihsel gelișimlerini incelemek amaçlanmıștır. Bu amaç doğrultusunda literatür taraması yöntemi kullanılmıștır. Literatür taraması ULAKBIM, ERİC, Scopus ve Google Akademik veri tarama tabanlarında gerçekleştirilmiştir. Sonuç olarak her ülkenin yükseköğretim yapısı farklı olması dolayısıyla yükseköğretim ombudsmanlığının uygulamaları farklılaşmakta olduğu sonucuna varılmıştır. Dünya genelinde yaygınlaşan yükseköğretim ombudsmanlık ofislerinin amacları, teșkilat yapıları, finansmanları ve kapsamlarının araştırılması gerekir. Türkiye’de yükseköğretim yapısının özellikleri dikkate alınarak örgütsel ombudsmanlık modeli geliștirilmelidir.
\end{abstract}

Anahtar kelime: yükseköğretim ombudsmanlı̆̆ı̈; örgütsel ombudsmanlık; ombudsman

\section{Higher Education Ombudsman Offices as an Organizational Ombudsmanal Application}

\begin{abstract}
With the development of classical ombudsman institutions, organizational ombudsman offices are also developing. Since the beginning of the 1960s, organizational ombudsman offices have become widespread in large enterprises, public service institutions and especially higher education institutions. In this study, it is aimed to examine the roles, functions and historical development of organizational ombudsman offices in the context of higher education institutions. For this purpose, literature review method has been used. The literature review was carried out on ULAKBIM, ERIC, Scopus and Google Scholar data search bases. As a result, it can be said that higher education ombudsman varies because each country has different higher education structure. The purpose, organizational structure, financing and scope of higher education ombudsman offices in worldwide should be investigated. Taking into account the characteristics of the structure of higher education in Turkey, organizational ombudsman model should be developed.
\end{abstract}

Keyword: higher education ombudsman; organizational ombudsman; ombudsman

\section{Giriș}

Küreselleşme ve demokratikleşme süreçleri klasik kamu yönetimi anlayışının değişimine neden olmuştur. Yeni kamu yönetiminde katılım, hesap verebilirlik, açılık ve şeffaflık gibi değerleri ön plana çıkartmıştır (Karaçor \& Oltulu, 2011). Devlet ile vatandaş arasındaki iş ve işlemlerin denetimi sağlamak amacıyla yargı organları yetersiz kalmış ve yeni denetim araçlarına ihtiyaç doğmuştur. Bu bağlamda klasik ombudsmalık kurumları önem kazanmaya başlamıştır (Ünal \& Erdoğan, 2017). İlk olarak İs-

*Yazışma Adresi / Address for Correspondence:

M. Kaya, Email:metinkaya439@gmail.com

Geliş Tarihi / Received Date: 16.09.2020

Kabul Tarihi / Accepted Date: 26.11.2020

Doi: $10.26701 /$ uad.796149 veç'te uygulanan klasik ombudsmanlık kurumu dünya çapında yaygınlaşmaya başlamıştır (Özekicioğlu, 2018).

Alanyazında üç farklı ombudsmanlık modelinde söz edilmektedir. Gadlin'e (2000) göre bu modeller; klasik ombudsmanlık, savunucu ombudsmanlık ve örgütsel ombudsmanlık modelleridir. Klasik ombudsmanlık devlet ile vatandaş arasında yaşanan uyuşmazlıklara odaklı bir modelidir. Savunucu ombudsmanlı bireylerin hak ve özgürlüklerini savunmaya odaklı ombudsmanlık modelidir. Örgütsel ombudsmanlık ise örgüt ile ve örgütün iç ve dış paydaşları arasındaki anlaşmazlıklara odaklı modeldir.

Klasik ombudsmanlık kurumlarının gelişimi ile birlikte örgütsel ombudsmanlık ofisleri/büroları da gelişmektedir (Posta, 2015). 1960 yılların başından itibaren büyük işletmelerde, kamu hizmeti yürüten kurumlarda ve özellikle yükseköğretim kurumlarında örgütsel ombudsman- 
lık ofisleri yaygınlaşmaya bașlamıștır (Özerdem, 2018; Kaygısız, 2016). Dünyada yükseköğretim kurumlarında ombudsmanlık ofislerine oldukça sık olarak rastlanmaktadır (Behrens, 2017). Türkiye' de de ilk ombudsmanlık uygulaması Altınbaş Üniversitesi'nde başlamıştır (Altınbaş Üniversitesi Öğrenci Ombudsmanlığı Yönergesi, 2019). Dünyada yaygınlaşmaya başlayan yükseköğretimde ombudsmanlık ofisleri çeşitli ülkelerde yükseköğretim yönetimi açısından önem kazanmaya başlamıştır. Bu bağlamda yükseköğretim kurumlarında örgütsel ombudsmanlık ofislerinin dünyadaki uygulamaları dikkate alınarak rollerinin ve işlevlerinin belirlenmesi gerekir.

Alanyazında yükseköğretim ombudsmanlık ofislerinin rolleri, işlevleri ve yapısına ilişkin çalışmalar oldukça kısıtlıdır. Bu çalışma ile yükseköğretim kurumlarında ombudsmanlık ofislerinin rolleri, işlevleri ve uygulamalarına ilişkin tartışmalara katkı sağlayacağı düşünülmektedir. Bu çalışmada yükseköğretim ombudsmanlık ofislerinin rolleri, işlevleri ve tarihsel gelişimi literatüre dayalı olarak incelemek amaçlanmıştır. Bir örgütsel ombudsmanlık uygulaması olarak yükseköğretim ombudsmanlık ofislerinin tarihsel gelişimi, uygulanma gerekçeleri, ilkeleri, rolleri ve işlevleri nelerdir sorusuna yanıt aranmıștır.

\section{YÖNTEM}

$\mathrm{Bu}$ çalışmanın yöntemi literatür taramasıdır. Literatür taraması varolan kaynak ve belgeleri inceleyerek konuya veya araştırma problemine göre bilgilerin düzenlenmesi olarak ifade edilmektedir (Büyüköztürk, Akgün, Demirel, Karadeniz, \& Çakmak, 2015).Bu çalışmanın amacı doğrultusunda ombudsman, ombuds, ombudsperson, campus ombuds, university ombudsman, student ombudsman, education ombudsman, higher education ombudsman kelimeleri İngilizce anahtar kelime olarak; üniversite ombudsmanı, kampus ombudsmanı, eğitim ombudsmanı, yükseköğretim ombudsmanı ise Türkçe anahtar kelimeler olarak kullanılmıştır. Seçilen anahtar kelimeler kullanılarak literatür taraması yapılmıștır. Literatür taraması ULAKBIM, ERİC, Scopus ve Google Akademik veri tabanlarında gerçekleştirilmiştir. Veri tabanlarının ürettiği araştırmalar incelenmiş ve doğrudan örgütsel ombudsmanlıkla ilgili olan çalışmalar seçilmiştir. Ayrıca yükseköğretim ombudsmanlık uygulaması ile ilgili olarak daha çok atıf alan araştırmalar yer verilmiştir. $\mathrm{Bu}$ çerçevede, bu çalışmada örgütsel ombudsmanlığın gerekçeleri, tanımı, ilkeleri, işlevleri ve yükseköğretim kurumlarında gelişimine yer verilmiştir.

\section{YÜKSEKÖĞRETIM KURUMLARINDA OMBUDSMANLIK UYGULAMALARININ GEREKÇELERI}

Yükseköğretim kurumu olan üniversitelerde ombudsmanlık uygulanmasının çeşitli gerekçeleri öne sürülmektedir. Bu gerekçeler örgütsel çatışma yönetimi için bir strateji olma, örgütsel şikayet yönetimi için bir mekaniz- ma olma ve örgütsel psiko-sosyal risk ve tehlikeleri azaltmak için önleyici bir mekanizma olmadır (Rowe \& Gadlin, 2014; Kaya, 2019; Met, 2016). Bu gerekçeler aşağıdaki başlıklar altında ayrıntılı olarak sunulmuştur.

\section{1. Örgütsel çatışma yönetimi ve örgütsel ombudsmanlık}

Örgütsel çatışma örgütün paydaşları arasında yaşanan anlaşmazlık ve uyumsuzluk durumlarını ifade etmektedir (Koçel, 2010; Ural, 2018). Örgütlerde insanlar birbirleri ile sürekli etkileşim halindedir. Bu etkileşim ortamı içerisinde örgüt paydaşlarının çıkarları, amaçları, niyetleri ve eylemleri birbirleriyle çatışmaktadır. Bu çatışma örgütler için aynı zamanda kaçınılmazdır. Örgütsel çatışmaların kaynağı örgütün paydaşları arasında çıkarların çatışmasından kaynaklanabildiği gibi örgüt paydaşlarının örgütsel statü ve güç farklarından kaynaklanabilmektedir (Karip, 2010). Örgütsel çatışmaları en az düzeye indirebilmek için çeşitli çatışma yönetim stratejilerinden söz edilmektedir. Rahim'e (2002) göre bu çatışma yönetim stratejileri bütünleștirme, ödün verme, uzlaşma, hükmetme ve kaçınmadır. Rahim'e (2002) göre bu stratejilerinin odaklandığı durumlar aşağıdaki gibidir. Bütünleşme stratejisinde tarafların karşıllklı kabul edebilecekleri bir çözüm üretmek amaçlanmaktadır. Ödün verme stratejisinde taraflardan birinin hakkından ödün vererek çatışma konusu ortadan kaldırmak hedeflenmektedir. Uzlaşma stratejisinde taraflar hem kendi ihtiyaçları hem de karşı tarafın talepleri dikkate alarak çatışmayı çözmeyi amaçlamaktadırlar. Hükmetme stratejisinde ast-üst ilişkinin dikkat çekici düzeyde olduğu durumlarda taraflardan biri olan üstün, istek ve ihtiyaçlarına dayalı olarak çatışmayı çözüme kavuşturmak amaçlanır. Kaçınma stratejisinde çatışma konusunu görmemezlikten gelinerek kendiliğinden çözüme kavuşturmak hedeflenmektedir.

Sözü edilen çatışma yönetim stratejileri çatışan kişi ve gruplar arasındaki ilişkilere odaklı stratejilerdir. Ombudsmanlık ofisleri ise çatışma konusuna ilişkin bağımsız aracı bir unsur olması açısından diğer çatışma yönetim stratejilerinden ayrılmaktadır. Başka bir ifade ile çatışmaların yönetimi için taraflar arasında tarafsız ve bağımsız bir üçüncü bir unsur araya girmektedir. Taraflar arasına giren bir üçüncü unsur olarak ombudsmanlık ofisi veya ombudsmanın odağında çatışmaya konu olan problemin çözümleri vardır. Ombudsmanlık ofislerinin çatışma yönetimi için farklı bir strateji veya uygulama olması dikkate çekicidir.

\section{2. Şikayet yönetimi ve örgütsel ombudsmanlık}

Örgütlerde çatışma konularının yansıdığı önemli göstergelerden biri örgüt paydaşları tarafından yapılan şikâyetlerdir. Şikayet kavramı bireylerin örgütün ürettiği hizmet veya üründen memnun olmama durumunu ifade etmektedir (Alabay, 2012; Görmüş \& Aydın, 2013 ). Şikayet yönetimi ise örgütten hizmet alan ve örgütte hizmet üretenlerin memnuniyetlerini sağlamaya yönelik bir süreçtir 
(Alabay, 2012). Örgütler çeşitli şikayet yönetim sistemleri geliştirmektedirler. Dilekçe ile şikayet başvuruların dışında telefon ve online şikayet hatları ile örgüt paydaşlarının şikayetleri alınmakta ve incelenmektedir (Tokay Argan \& Aricl, 2019).

Ombudsmanlık ofisleri ise şikayetçi ile ombudsman arasında şikayet konusu hakkında yüz yüze gerçekleșen bir süreçtir. Bu süreçte şikayet konusuna ilişkin karşılıklı bilgilendirme olduğu gibi şikayet konusuna ilişkin çözüm yöntemleri de geliştirmektedir. Ayrıca ombudsmanlık ofislerinde şikayet konusu derinlemesine incelenmektedir. Öte yandan şikayet konusuna ilişkin çözüm seçenekleri şikayetçi ve ombudsman arasında ortaya konmaktadır. Yüksek öğretim kurumları şikayetin yoğun yaşandığı büyük organizasyonlardır (Kaya, 2019 Görmüş, Aydın \& Aydın 2013). Üniversitelerin iç ve dış paydalarını çeşitliği ve büyüklüğü dikkate alındığında ombudsmanlık ofislerinin etkin bir şikayet yönetim mekanizması olarak değerlendirilebilir.

\subsection{Psiko-sosyal riskler ve örgütsel ombudsmanlık}

İş güvenliği ve iş sağlığının önemli bir boyutu çalışma ortamında karşılaşılan psiko-sosyal risklerdir (Çögenli, 2019). Çalışma ortamında karşılaşılan psiko-sosyal riskler stres, şiddet, yıldırma gibi davranışlardır (Vatansever, 2014). Çalışma ortamında iş güvenliği ve sağlığının sağlanması örgütlerin amaçlarından biridir. Örgütler çalışma ortaminda psiko-sosyal riskleri ve tehlikeleri ortadan kaldırmak için tedbirler alması gereklidir. Örgütlerdeki psiko-sosyal riskleri azaltmak için önleyici bir mekanizma olarak örgütsel ombudsmanlık etki olabilir (Met, 2016).

\section{4. ÖRGÜTSEL OMBUDSMANLIK}

Ombudsman kelimesi temsil eden, sözcü olan, vekil, arabulucu ve savunucu gibi anlamları farklı dillerde içermektedir (Giși,2017; Sezen, 2001). Ombudsman kelimesi Türkçe 'de ise kamu denetçisi olarak ifade edilmektedir. Genel anlamda ombudsmanlık bașka bir ifade ile klasik ombudsmanlık yasama organı tarafından seçilen, hükümetten bağımsız, devlet ile vatandaş arasındaki uyuşmazlıklara çözüm önerileri getiren kurum olarak tanımlanmaktadır (Okur, 2016; Gişi, 2017)

Örgütsel ombudsmanlık ise bir örgüt içerisinde yaşanan çatışmaları çözmek amacıyla görev yapan yardımcı bir örgütsel birim olarak tanımlanmaktadır (Charles, 2010). Öte yandan Posta (2015) örgütsel ombudsmanlığı bir örgüt içerisinde belirlenmiş tarafsız ve örgütün üst yönetimine rapor veren birim olarak tanımlanmaktadır. $\mathrm{Bu}$ tanımların yanında ombudsman bir örgüt içerisinde çatışmaları çözmek ve şikayetleri çözüme kavuşturmak için seçilmiş yada görevlendirilmiş kişi olarak ifade edilmektedir. Örgütsel birim olarak ombudsman ofisi seçilmiş veya görevlendirilmiş ombudsmanlar tarafından temsil edilir. Yine Posta (2015) göre örgütsel ombudsmanı örgüt kapsamında karşılaşılan çatışmalara ilişkin olarak arabuluculuk, koçluk, diplomatik müzakere ve uzlaşma yöntemlerini kullanan bağımsız kişiler olarak ifade etmektedir. Örgütsel ombudsmanlar bu yöntemleri kullanırken gizli, gayrı resmi, tarafsız ve bağımsız olarak hareket eder (Holmes, 2012).

\section{1. Örgütsel ombudsmanlığın temel ilkeleri}

Örgütsel ombudsmanlık ofislerinin temel ilkeleri bağımsızlık, tarafsızlık, gizlilik ve gayri resmiliktir (Shelton, 2000). Bu ilkelerin özellikleri Uluslaraarası Ombudsmanlık Birliği'ne (International Ombudsman Association) göre aşağıdaki gibidir (International Ombudsman Association, 2009).

Bağımsızlık: Bağımsızlık ilkesi, ombudsmanlık ofisi ve ombudsman hem içinde bulunduğu örgütten hem de diğer örgütlerden bağımsız olarak hareket etmesi olarak tanımlanmaktadır. Ombudsmanlık ofisi ve ombudsman örgüt içerisinde herhangi bir yönetici ve görevli memurun kontrol, sınırlandırma ve müdahalelerinden bağımsız olarak harekat eder. Ombudsman yasaların ve yönetmeliklerin izin verdiği ölçüde örgütsel bilgi, belge ve kişilere erișebilir. Ombudsman, ombudsmanlık ofisi personelini seçme, ombudsmanlık ofisi bütçesini yönetime yetkisine sahiptir. Ombudsmanlık büroları ve ombudsman hazırladığı raporları doğrudan en üst yöneticiye iletir. Örgün herhangi bir birimine yapısal olarak bağlı değildir.

Tarafsızlık: Tarafsızlık ilkesi, ombudsmanlık ofisi ve ombudsman örgüt içerisindeki problemlerin tarafları ve çatışmanın tarafları arasında yansız hareket etmesi olarak tanımlanır. Ombudsmanlık ofisleri ve ombudsman çatışmaya ve probleme taraf olan bireyler veya görevliler arasında eşitlik ve adillik ilkesine göre hareket eder. Ombudsmanlık ofisi ve ombudsman tarafsızlıklarını riske ve tehlikeye atacak ilişkilerden uzak hareket eder. Bu ilişkiler örgüt içerisinde diğer birimlerle, derneklerle ve görevli kişiler ilişkiler olabilir. Ombudsmanlık ofisi ve ombudsman çatışmaya konu olan taraflardan herhangi birini temsil etmez. Ombudsmanlık ofisleri ve ombudsman catışma taraflarından herhangi birini savunmazlar.

Gizlilik: Gizlilik ilkesi, ombudsmanlık ofisi ve ombudsmandan yardım alan kişilerle ilgili tüm iletişim bilgilerinin ve iletişim içeriklerinin güven altına alınması alarak tanımlanmaktadır. Başka bir ifade ile ombudsmanlık ofisini başvuran birey ile ombudsman arasındaki iletişim ayrıcalıklıdır ve gizli tutulur. Ombudsmanlık ofisine başvuran bireylerin kimlik bilgileri saklı tutulur. Ombudsmanlık ofisini başvuran bireylerin kimlikleri ortaya çıkaracak bilgileri gizli tutar. Ayrıca ombudsmanlık ofisi bireyi tanımlayacak kayıtlar tutmaz. Ombudsman raporlarını düzenlerken gizlilik ilkesini gözetir. Ombudsmanlık ofisi ile yapılan görüşmeler ve diğer iletişimler içerikleri herhangi bir birime ve yönetime bildirilmez.

Gayri resmilik: Gayri resmilik ilkesi, ombudsmanlık ofisi ve ombudsman resmi bir işlem yapmadan problemlerinin çözümüne yardımcı olması olarak tanımlanmaktadır. Ombudsmanlık gayri resmi bir şekilde işlev görmektedir- 
ler. Ombudsman dinleme bilgi alma, bilgi verme, sorun tespit etme, çözüm için seçenek geliştirme gibi işlevleri yerine getirmektedir. Ombudsmanlık ofisi ve ombudsmanın bu işlevleri yerine getirmesinin temel amacı karşılaşılan problemi başvuran kişinin çözmesini sağlamaktır. Ombudsmanlık ofisi ve ombudsman örgüt için bağlayıcı kararlar vermez, politikalar düzenlemez ve resmi bir birim olarak karar vermez.

\section{2. Örgütsel ombudsmanlık ofisinin görevleri}

Örgütsel ombudsmanlık ofislerinin temel iki görevinde söz edilmektedir. Rowe ve Gadlin' ne (2014) göre birinci temel görevi örgütün iç ve dış paydaları arasında güvenilir, şeffaf ve adil ve kolay erişebilir bir ilişki ortamı hazırlamaktadır. İkinci temel görevi ise örgütün çatışma kaynakları, çatışmaların çözüm yöntemleri gibi genel olarak örgütün çatışma yönetimi sistemi örgüt paydaşlarının anlamasını sağlamaktır.

\section{3. Örgütsel ombudsmanlık ofisinin işlevleri}

Örgütsel ombudsmalık ofislerinin örgüte yönelik ve bireylere yönelik çeşitli işlevleri yerine getirmektedir (Rowe \& Gadlin, 2014; Bennett, 2014; Rowe, 1995 ) Örgüte yönelik işlevleri ve bireye yönelik işlevleri maddeler halinde sunulmuştur.

\subsection{1. Örgüte yönelik ișlevleri}

1.Ombudsmanlık ofislerine herhangi bir şikayet, mağduriyet veya danışma amaçlı başvuranların örgüt paydalarının kaygı ve endişeleri teyit edilir. Danışan veya şikayette bulunun konuya ilişkin örgütün politikaları, ilkeleri, kuralları ve uygulamaları ile bilgi verilir ve açıklamalar yapilir.

2.Ombudsmanlık bürolarına herhangi bir şikayet, mağduriyet veya danışma amaçlı başvuran örgüt paydaşı aktif olarak dinlenir ve karşılık bir diyalog şeklinde iletişim gerçekleştirilir.

3. Şikayet, mağduriyet veya danışma konusuna ilişkin yüz yüze bilgi edinme imkanı doğar.

4.Örgütsel olarak denetimi ihmal edilen, dikkatten ve gözden kaçan sorunların tespit edilmesini sağlar. Tespit edilen bu tür konuların nedenleri ortaya konur.

5.Ombudsmanlık ofislerine herhangi bir şikayet, mağduriyet veya danışma amaçlı başvurulan konularda derinlemesine bir araştırma yürütülür.

6.Ombudsmanlık ofislerinin gündemine alınan sorunlara ilişkin çözüm önerilerinin ve çözüm seçeneklerinin geliştirilir.

7.Örgüt yöneticileri ve çalışanlar karşılaştıkları problemlere yönelik farklı çözüm yöntemleri ve stratejiler sunar.

\subsubsection{Bireye yönelik ișlevleri:}

1.Örgüt çalışanlara problem çözme ve çatışma yönetimi ilişkin farklı kaynaklar sunar.
2.Ombudsmanlık ofisine bașvuranlara problemleri ile ilgili kendi kendilerine çözüm üretebilme imkanı sağlar.

\section{DÜNYADA YÜKSEKÖĞRETIM ALANINDA ÖRGÜTSEL OMBUDSMANLIK UYGULAMALARIN GELIŞIMI}

Klasik ombudsmanlık öncelikle devlet ve vatandaş arasındaki uyuşmazlıkları çözmek için kurumsallaşmaya başlamıştır. İskandinav ülkelerindeki ombudsmanlık kurumları diğer ülkeler tarafından model alınmıştır. Klasik ombudsmanlık kurumlarının gelişimi örgütsel ombudsmanlık kurumları izlemiştir. Büyük organizasyonlar ve yüksek öğretim kurumlarında örgütsel ombudsmanlık kurumları yaygınlaşmaya başlamıştır. Yükseköğretim kurumlarında şikayetleri ve çatışmaları çözmek amacıyla ombudsmanlık ofisleri gelişmeye başlamıştır (Birdişli, 2011).

İlk üniversite ombudsmanlığı Kanada 'da Simon Fraser Üniversitesi bünyesinde 1965 yılında kurulmuştur. Simon Fraser Üniversitesi ombudsmanlık ofisi öğrenci girişimleri ile kurulmuştur (Kaygısız, 2016). Ayrıca sözü edilen ombudsmanlık ofisinin finansmanı öğrenciler tarafından karşılanmıştır. Bu finansman şekli 2007 kadar sürdürülmüş ve bu yıldan itibaren üniversite yönetimi tarafından finanse edilmeye başlamıştır (Özerdem, 2018). 1967 yılında Amerika birleşik devletlerinde Michigan Devlet Üniversitesi ombudsmanlık ofisi açılmıştır. Michigan Devlet Üniversitesi'ndeki ombudsmanlık uygulaması Amerika Birleşik Devletleri'ndeki diğer üniversitelere örnek olmuştur. Amerika Birleşik Devletleri'nde ombudsmanlık ofisleri yayınlaşma ve popülerleşmeye başlamıştır ( Bennett, 2014). Kanada ve Amerika Birleşik Devletleri'nde uygulamaya başlayan ombudsmanlık ofisleri diğer ülkelere de örnek teşkil etmiştir. 1970'lı yıllarda Avusturalya; 1980 yıllarda batı Avrupa ülkelerinde ve Güney Amerika ülkelerinde yükseköğretim kurumlarında ombudsmanlık ofisleri açılmaya başlamıştır (Behrens, 2017).

Yükseköğretim kurumlarında ombudsmanlık uygulaması 2000'li yıllarda farklı bir dönüşüm yaşamıştır. Bir batı Avrupa ülkesi olan İspanya her bir üniversitenin ombudsmanlık ofisi açmasını ve bir ombudsman seçilmesini 2001 yılında yasal zorunluk haline getirmiştir. Benzer şekilde Belçika' da 2004; Avusturalya'da 2008 yılı itibari ile üniversite ombudsmanlık ofislerinin açılması yasal zorunluk haline gelmiştir (Özerdem, 2018).

2000’li yıllarda yaşanan diğer bir önemli dönüşüm ise yükseköğretim ombudsmanlık uygulamalarının farklı formlara dönüşmesidir. Hırvatistan (2008), Portekiz (2010) ve Norveç (2013) gibi ülkelerde öğrenci ombudsmanlığı şeklinde yükseköğretim ombudsmanlıkları kurulmuştur. Almanya' da ise farklı sorunlara çözüm getiren farklı ombudsmanlık çeşitleri oluşturulmuştur (Özerdem, 2018). 


\section{TÜRKIYE'DE YÜKSEKÖĞRETIM}

\section{ALANINDA ÖRGÜTSEL OMBUDSMANLIK} UYGULAMALARININ GELIŞIMI VE ALTINBAŞ ÜNIVERSITESI ÖĞRENCI OMBUDSMANLIĞI

\section{ÖRNEĞI}

Türkiye'de bazı araştırmacılar tarafından yükseköğretim kurumlarında ombudsmanlık uygulaması tartışılmaktadır (Özerdem, 2018; Kaygısız, 2018; Birdişli, 2011; Kaya, 2019; Met, 2016). Öte yandan 2019 yılında bir vakıf üniversitesi olan Altınbaş Üniversitesi'nde öğrenci ombudsmanlığı ofisi kurulmuştur (Altınbaş Üniversitesi Öğrenci Ombudsmanlığı Yönergesi, 2019).

Altınbaş Üniversitesi Öğrenci Ombudsmanlığı Yönergesi’ne (2019) göre Altınbaş Üniversitesi ombudsmanlığ sadece örgüt paydaşı olarak öğrencilere odaklı bir ombudsmanlıktır. Altınbaş Üniversitesi Öğrenci Ombudsmanlığı, ombudsman ve uzman personelden oluşmaktadır. Ombudsman ve uzman personel rektörlük tarafından atanmaktadır. Öğrenci ombudsmanlık ofisinin temel görevi ombudsmanlığa ulaşan şikayetleri ve dilekleri ilgili birimlere iletmek ve öğrenci memnuniyeti ile ilgili raporlar hazırlamaktır. Sözü edilen öğrenci ombudsmanlık ofisinin daha çok bir şikayet yönetim sistemi olarak kurulmuş olduğu söylenebilir. Öte yandan Türkiye'de örgütsel ombudsmanlık ofisinin ilk uygulaması olması açısından önemlidir.

\section{SONUÇ}

$\mathrm{Bu}$ çalışmada bir örgütsel ombudsmanlık uygulaması olan yükseköğretimde ombudsmanlık ofisleri konusu literatür taraması yöntemi ile incelenmiştir. Yüksek öğretim ombudsmanlığının tarihsel gelişimi, örgütsel yapısı, rolleri ve işlevleri açıklanmıştır. Dünyada bazı üniversitelerde ombudsmanlık bürolarının kurulması üniversitelerin yönetim yetkisi altında iken bazı ülkelerde ise yasal zorunluk konumundadır. Almanya'da şikayet ya da çatışma konusuna göre çeşitli ombudsmanlık ofisleri varken İspanya gibi ülkelerde üniversite ombudsmanlığı yasal bir zorunluktur. Öte yandan bazı ülkelerde üniversite ombudsmanlığı öğrenci odaklı şikayetlerin ve çatışmaların çözümlendiği ofisler şeklidedir. Kimi üniversitelerde ise tüm yükseköğretim paydaşlarını kapsamaktadır. Her ülkenin yükseköğretim yapısı farklı olmasından dolayı ile yükseköğretim ombudsmanlığının çeşitlendiği söylenebilir. Türkiye'nin yükseköğretim yapısı kendine özgü olması sebebi ile üniversite ombudsmanlığının gerekli olup olmadığı tartışılmalıdır. Özerdem'e (2018) göre Türkiye'de yükseköğretim ombudsmanlığının işlerlik kazanması hem üniversitelerin uluslararasılaşmasına hem de üniversite personeli ve öğrencilerin aidiyetlik duygularının gelişmesine katkı sağlayacaktır. Ayrıca yükseköğretim ombudsmalı ofislerinin kurulması ile proaktif bir sorun çözme mekanizması olarak Türk eğitim sistemine katkı sağlayacağını ifade etmektedir.

Yükseköğretim bağlamında örgütsel ombudsmanlık ofis- leri çatışma yönetimi, şikayet yönetimi ve örgüt ortamında psiko-sosyal risk ve tehlikelerin önlenmesi için bir araç olarak işlev görmektedir. Kaygısız'a (2018) göre yükseköğretim ombudsmanlığı iletişim ortamını iyileştirmek, kişisel ihlalleri ve haksızları ortan kaldırmak, öğrencilerin eğitim haklarının korunması sağlamak, hem üniversite personelinin hem öğrencilerin üniversiteye yabanc1laşmasını önlemek gibi yükseköğretim kurumlarına katkı sağlayabilir. Öte yandan yükseköğretim ombudsmanlık ofisleri ile birlikte yükseköğretimde bürokratik iş yükünün azalacağını da ifade etmektedir. Birdişli'e (2011) göre Türkiye'de yükseköğretim kurumlarının niceliksel büyümesi ve yükseköğretim hizmeti alan öğrencilerin giderek artması hem üniversitelerin hem öğrencilerin sorunlarının çözümünde üniversite yönetiminin yetersiz kalmasına neden olmaktadır. Hem üniversite personelinin hem de üniversite öğrencilerinin şikâyetleri ve dilekleri artmaktadır. Bu şikayetlerin merkezden çözümüne alternatif olarak yerinden çözümünün sağlanmasında ombudsmanlık ofislerinin katkı sağlayacağını ifade etmektedir. Bunun yanında yükseköğretim kurumlarında ombudsmanlık ofislerinin kurulmasını önermektedir. Dünya gelinde yaygınlaşan yükseköğretim ombudsmanlık ofislerinin amacı, teşkilat yapısı, görevleri, finansmanı ve kapsamının araştırılması gerekir. Türkiye'de yükseköğretim yapısının özellikleri dikkate alınarak örgütsel ombudsmanlık modeli geliştirilmelidir.

\section{KAYNAKLAR}

Alabay, M., N. (2012). Müşteri şikâyetleri yönetimi. Uluslararası Yönetim Iktisat ve Işletme Dergisi, 8(16), 137-157.

Altınbaş Üniversitesi Öğrenci Ombudsmanlığı Yönergesi (2019). 30.04.2020. tarihinde http://www.altinbas.edu.tr/ Files/users/fundatasdelen/\%C3\%96\%C4\%9Frenci\%200mbudsmanl\%C4\%B1\%C4\%9F\%C4\%B1\%20Y\%C3\%B6nergesi. pdf adresinden erişilmiştir.

Behrens, R. (2017). Being an ombudsman in higher education. A comparative study, 30.04 .2020 tarihinde http://www. enohe.net/wp-content/uploads/2017/06/Being-an-ombudsman.pdf adresinden erişilmiştir

Bennett, D., M. (2014). Roles and functions of organizational ombuds officers in the United States. Electronic Theses and Dissertations. 67. 30.04.2020 tarihinde https://digitalcommons.du.edu/cgi/viewcontent.cgi?article $=1066 \&$ context $=$ etd adresinden erişilmiştir.

Birdişli, F. (2011). Yeni kamu yönetimi yaklaşımı bağlamında kamu denetçiliği ve bir denetim aracı önerisi olarak üniversite ombudsmanlığı. Y. Koçak, A., \& C. Çiçek (Ed), Kamu Yönetimi, Yönetim-Siyaset Sorunlar ve Yeniden Yapılanma, 111-136. SFS Grup Yayınevi, Ankara.

Charles, H. (2010) The organizational ombudsman: Origins, roles and operations - a legal guide, Chicago: IL, American Bar Association.

Çögenli, M., Z. (2019). İs sağlığı ve güvenliğinde psikososyal yaklaşımlar. Konya: Eğitim Yayınevi.

Gişi, S. (2017). Ombudsmanlık kurumu, İsveç ve Fransa ülke uygulamaları ile Avrupa ombudsmanı üzerine bir inceleme. Yıldırım Beyazıt Hukuk Dergisi, (2), 1-42. 
Görmüş, A. Ş., Aydın, S., \& Aydın, M. (2013). Yükseköğretim kurumlarında öğrenci şikâyetlerinin ve şikâyet yönetiminin değerlendirilmesi. Uşak Üniversitesi Sosyal Bilimler Dergisi, 6(3), 167-190.

International Ombudsman Association (2009). IOA best practices a supplement to IOA's standards of practice. 29.04.2020 tarihinde https://www.ombudsassociation.org/ assets/docs/IOA_Best_Practices_Version3_101309_0.pdf adresinden erişilmiştir.

Karaçor, S., \& Oltulu, A. (2011). Demokrasi ve yönetişim boyutu ile yeni kamu yönetimi anlayışı. Sosyal Ekonomik Araştırmalar Dergisi, 11(22), 403-418.

Karip, E. (2010). Çatışma yönetimi. Ankara: Pegem Yayıncılık.

Kaya, M. (2019). Eğitim kurumlarında şikâyet yönetimi: Ombudsmanlık raporlarının incelenmesi. Kocaeli Üniversitesi Eğitim Dergisi, 2(1), 1-12.

Kaygısız, Ü. (2016). Yükseköğretimde kampus ombudsmanlığı. Journal of International Social Research, 9(43), $1917-$ 1926.

Kaygısız, Ü. (2018). Üniversitelerde uyuşmazlık çözümü aracı olarak kampus ombudsmanlığı: öğrencilerin algılarını ölçmeye yönelik bir analiz. Ombudsman Akademik, (8), 125140.

Kayıkcı, S. (2018). Yönetişimin kamu kurumlarında uygulanabilirliği: Yükseköğretim kurulu başkanlığı örneği. Ombudsman Akademik, (1), 163-181.

Koçel, T. (2010). İşletme yöneticiliği yönetici geliştirme organizasyon ve davranış. İstanbul: Beta Yayınlar.

Met, Ö., L. (2016). Çalışma yaşamında psikososyal risklere proaktif bir yaklaşım: Örgütsel ombudsmanlık modeli. Sosyal Bilimler Dergisi Sayı:49,94-114.

Okur, Y. (2016). Ombudsmanlık kurumu: Tarihi gelişim ve Türkiye'de başlangıçta birkaç öneri. Denetişim, (6), 71-83.

Özekicioğlu, S. (2018). Ombudsmanlık mekanizmasının gelişimi: Avrupa birliği ve Türkiye bağlamında değerlendirilmesi. Yönetim ve Ekonomi Araştırmaları Dergisi, 16(1), 158-175.

Özerdem, F. (2018). Dünyada yükseköğretim sisteminde ombudsmanlık kurumunun gelişimi ve Türk yükseköğretim sisteminde ombudsmanlık sisteminin getirilmesine dair öneriler. Elektronik Siyaset Bilimi Araştırmaları Dergisi, 9(16), 71-84.

Rahim, M., A. (2002). Toward a theory of managing organizational conflict. International Journal of Conflict Management, 13(3), 206-235.

Rowe, M., \& Gadlin, H. (2014). The organizational ombudsman. In W. K. Roche, P. Teague, \& A. J. S. Colvin (Eds.), The Oxford handbook of conflict management in organizations (210232). Oxford: Oxford University Press.

Sezen, S. (2001). Ombudsman: Türkiye İçin Nasıl Bir Çözüm? Amme idaresi Dergisi, 34 (4), 71-96.

Shelton, R., L. (2000). The institutional ombudsman: A university case study. Negotiation Journal, 16(1), 81-98.

Büyüköztürk, Ş., Akgün, Ö. E., Demirel, F., Karadeniz, Ş., \& Çakmak, E. K. (2015). Bilimsel araştırma yöntemleri. Ankara, Pegem Akademi Yayıncılık.

Tokay Argan, M., \& Arıcı, A. (2019). Sağlık iletişiminde e-şikayet: Hastaların ve hasta yakınlarının sikayetvar. com paylaşım- ları üzerine bir araştırma. Akdeniz İletişim, (31), 339-355.

Ural, A. (2018). Örgütsel çatışmanın yönetimi. 1. Baskı, Ankara: Pegem Akademi Yayıncılık,

Ünal, F., \& Erdoğan, S. (2017). Kamu yönetiminin denetimi anlayışında dönüşüm ve ombudsmanlık kurumu. Dumlupınar Üniversitesi Sosyal Bilimler Dergisi (Özel Sayısı), 623-634.

Vatansever, Ç. (2014). Risk değerlendirmede yeni bir boyut: Psiko-sosyal tehlike ve riskler. Çalışma ve Toplum, 40(1),117138. 